AperTO - Archivio Istituzionale Open Access dell'Università di Torino

\title{
Cell-specific regulation of Ferroportin transcription following experimentally-induced acute anemia in mice
}

\section{This is the author's manuscript}

Original Citation:

Availability:

This version is available http://hdl.handle.net/2318/122484

since

Published version:

DOI:10.1016/j.bcmd.2012.08.002

Terms of use:

Open Access

Anyone can freely access the full text of works made available as "Open Access". Works made available under a Creative Commons license can be used according to the terms and conditions of said license. Use of all other works requires consent of the right holder (author or publisher) if not exempted from copyright protection by the applicable law. 


\section{UNIVERSITÀ DEGLI STUDI DI TORINO}

This Accepted Author Manuscript (AAM) is copyrighted and published by Elsevier. It is posted here by agreement between Elsevier and the University of Turin. Changes resulting from the publishing process - such as editing, corrections, structural formatting, and other quality control mechanisms may not be reflected in this version of the text. The definitive version of the text was subsequently published in:

Chiabrando D, Fiorito V, Marro S, Silengo L, Altruda F, Tolosano E., “Cell-specific regulation of Ferroportin transcription following experimentally-induced acute anemia in mice", Blood Cells Mol Dis. 50(1): 25-30 (2013) doi: 10.1016/j.bcmd.2012.08.002.

You may download, copy and otherwise use the AAM for non-commercial purposes provided that your license is limited by the following restrictions:

(1) You may use this AAM for non-commercial purposes only under the terms of the CC-BY-NC-ND license.

(2) The integrity of the work and identification of the author, copyright owner, and publisher must be preserved in any copy.

(3) You must attribute this AAM in the following format: Creative Commons BY-NC-ND license (http://creativecommons.org/licenses/by-nc-nd/4.0/deed.en),

http://www.sciencedirect.com/science/article/pii/S1079979612001532 
Cell-specific regulation of Ferroportin transcription following experimentally-induced acute anemia in mice

Deborah Chiabrando ${ }^{1}$, Veronica Fiorito ${ }^{1}$, Samuele Marro $^{2}$, Lorenzo Silengo ${ }^{1}$, Fiorella Altruda ${ }^{1}$ and Emanuela Tolosano ${ }^{1}$

${ }^{1}$ Dept. of Genetics, Biology and Biochemistry and Molecular Biotechnology Center, University of Torino, Italy.

${ }^{2}$ Institute for Stem Cell Biology and Regenerative Medicine, Stanford University School of Medicine, 265 Campus Drive, Stanford, CA 94305, USA

\section{Corresponding author:}

Emanuela Tolosano, $\mathrm{PhD}$

Molecular Biotechnology Center

Via Nizza 52, 10126 Torino, Italy

Phone: +39-011-6706423; Fax: +39-011-6706432

email: emanuela.tolosano@unito.it 


\section{Abstract}

Ferroportin (FPN), the sole characterized iron exporter, is mainly controlled by the peptide hormone hepcidin in response to iron, erythroid factors, hypoxia, and inflammation. In addition, intracellular iron level controls FPN translation by modulating the binding of Iron Responsive Proteins at the 5'UTR of FPN mRNA. Recently, Hypoxia Inducible Factor (HIF) $2 \alpha$ has been shown to regulate FPN expression in intestinal cells.

Here we show that, during experimentally-induced acute anemia in mice, FPN is regulated at transcriptional level in a cell-specific manner. FPN mRNA level increases in duodenum and spleen macrophages, whereas it does not change in liver and is strongly down-regulated in erythroid precursors. These results were confirmed in Caco2 Raw264.7 and K562 cells treated with a hypoxic stimulus. Moreover, we found a differential expression of HIF1 $\alpha$ and HIF2 $\alpha$ in cells and tissues that might account for the specificity of FPN regulation.

Thus, hypoxia, by directly controlling hepcidin and its target FPN, orchestrates a complex regulatory network aimed at ensuring rapid iron recovery from the periphery and efficient iron utilization in the erythroid compartment. 


\section{Introduction}

Iron homeostasis is maintained through the tight regulation of iron absorption by the intestine, iron recycling by macrophages and iron utilization mainly for hemoglobin synthesis [1]. Ferroportin (FPN) plays a crucial role in iron homeostasis being the only known iron exporter responsible for iron delivery from enterocytes and macrophages to the plasma, and for iron export from tissues stores $[2 ; 3]$.

FPN expression is mainly regulated at a post-translational level by the peptide hormone hepcidin [4]. Following hepcidin binding to FPN, FPN is internalized, phosphorylated and subsequently degraded by lysosomes [5;6]. When hepcidin concentration is low, the rate of FPN synthesis is greater than its degradation, resulting in higher amounts of FPN at the cell surface, thus increasing iron export. On the contrary, high hepcidin levels lead to FPN degradation and consequently to iron retention.

Moreover, FPN expression is regulated at a post-transcriptional level by intracellular iron concentration through the Iron Responsive Element (IRE) located in the 5'-untranslated region (UTR) of its mRNA [7;8]. The importance of this element is highlighted by alterations in iron homeostasis seen in Pmc mice bearing a deletion in the FPN promoter region, which alters transcription start sites and eliminates the IRE in the 5'-UTR [9].

Recently, Taylor and co-authors demonstrated that FPN was induced under conditions of low iron by the transcription factor Hypoxia Inducible Factor (HIF)2 $\alpha$ [10].

Finally, other papers demonstrated that FPN expression is also regulated at the mRNA level by hemoglobin/heme, hypoxia and inflammation $[3 ; 11 ; 12 ; 13 ; 14 ; 15 ; 16]$. 
The aim of this work is to analyse FPN regulation after acute anemia, a pathologic condition characterized by enhanced erythropoiesis, increased iron absorption and recycling, and rapid iron mobilization from hepatic stores.

\section{Materials and Methods}

\section{Mice and treatment}

Three month-old wild-type 129Sv male mice were used for experiments. Phlebotomy was performed by retro-orbital bleeding: a total of $1.5 \mathrm{ml}$ of blood was extracted in two lots over 48 hours. Experiments were performed 1, 3 and 7 days after the first bleeding. Hematological parameters were determined by using an automatic analyzer (Dasit Sysmex XE-2100).

All experiments were approved by the animal studies committee of the University of Torino (Italy).

\section{Determination of Tissue Iron Content}

Mice were perfused via the aorta with PBS and non-heme tissue iron content was determined as previously reported [13].

Western blotting 
Fifty $\mu \mathrm{g}$ of total protein extracts were separated on $8 \%$ SDS-PAGE and analyzed by Western blotting using antibodies against FPN [2] and actin (Santa Cruz Biothecnology Inc., Santa Cruz, California, USA).

\section{Quantitative real-time polymerase chain reaction}

Total RNA was extracted from tissue and cell samples using Micro-to-Midi Total RNA Purification System (Invitrogen, San Giuliano Milanese, MI, Italy). For quantitative real-time polymerase chain reaction (qRT-PCR), $1 \mu \mathrm{g}$ total RNA was transcribed into complementary DNA (cDNA) by M-MLV reverse transcriptase (Invitrogen) and random primers (Invitrogen). qRTPCR was performed on a 7300 Real Time PCR System (Applied Biosystems, Monza, Italy) using Universal Probe Library System (Roche Diagnostics Corp., Milano, Italy) as previously described [13]. Primers and probes are listed in Supplementary Table S1.

Nuclear protein extraction and Western blotting

Cells treated with $\mathrm{CoCl}_{2}$ were washed once in PBS and lysed in Buffer A (10 mM Hepes pH 7.9, $1.5 \mathrm{mM} \mathrm{MgCl}_{2}, 10 \mathrm{mM} \mathrm{KCl}, 0.5 \mathrm{mM}$ DTT) on ice for 15 minutes. Cells were lysed with a needle and then centrifuged for 20 seconds at $12000 \mathrm{~g}$. Supernatant was discarded, the pellet washed with PBS and resuspendend in Buffer B (20 mM Hepes pH7.9, 25\% (v/v) Glycerol, $0.42 \mathrm{NaCl}, 1.5$ $\mathrm{mM} \mathrm{MgCl} 2,0.2$ EDTA, $0.5 \mathrm{mM}$ DTT, 0.5mM PMSF, 1\% Protease Inhibitor (Roche) followed by rotation at $4^{\circ} \mathrm{C}$ for 30 minutes. After centrifugation at $12000 \mathrm{~g}$ at $4{ }^{\circ} \mathrm{C}$, the supernatant containing nuclei was collected, and protein concentration was determined using the Bio-rad Assay (Biorad, München, Germany). Fifty $\mu \mathrm{g}$ of nuclear protein extracts were separated on 10\% SDS-PAGE, and 
analyzed by Western blotting using a mouse monoclonal anti-HIF1 $\alpha$ antibody (NB100-105; Novus Biologicals), a rabbit polyclonal anti-HIF2 $\alpha$ antibody (NB100-122SS; Novus Biologicals) and a mouse monoclonal anti-HIF1 $\beta$ antibody (NB100-124; Novus Biologicals).

Spleen cell separation

Macrophages and erythroid precursor cells were isolated from spleen cell suspensions using CD11b and TER119 ferromagnetic microbeads respectively, according to the manufacturer's instructions (Miltenyi Biotec, Calderara di Reno, BO, Italy).

Cell culture and treatments

Raw264.7 cells (ATCC: TIB-71), K562 cells (ATCC: CCL-243'TM) and Caco2-cells (ATCC:

HTB- $37^{\mathrm{TM}}$ ) were used for in vitro experiments. Hypoxia on Raw Raw264.7 cells and K562 cells was chemically induced using cobalt chloride $\left(\mathrm{CoCl}_{2}\right.$; Sigma-Aldrich, Milano, Italy). After two hours of starvation, Raw264.7 and $\mathrm{K} 562$ cells were treated with $100-500 \mu \mathrm{M}$ of $\mathrm{CoCl}_{2}$ in culture medium without FCS, for different times. To block transcription, Actinomycin D (Sigma-Aldrich) was used together with $\mathrm{CoCl}_{2}$ treatment at different concentration (from 10 to $100 \mu \mathrm{g} / \mathrm{mL}$ ) for 24 hours.

For Caco-2 cells the hypoxia treatment was achieved by incubation for $6,24,48$ hours in a hypoxia chamber (Billups-Rothenberg Inc., Del Mar CA) containing 1\% oxygen., 5\% carbon dioxide and $94 \%$ nitrogen gas. 


\section{Results}

FPN is regulated in a tissue specific manner following phlebotomy

To gain an insight into the physiological response of FPN to experimentally-induced acute anemia in mice, we chose the bleeding model. A total of $1.5 \mathrm{ml}$ of blood was extracted by retro-orbital puncture (in two lots) over 48 hours. Experiments were performed 1, 3 and 7 days after the first bleeding. Red blood cells (RBCs), hemoglobin (HGB), and hematocrit (HCT) values were reduced by approximately $50 \%$ in phlebotomized mice 3 days after phlebotomy, while reticulocytes were increased by approximately $60 \%$. Expansion of the erythroid compartment was confirmed by the two-fold increase in spleen/body weight ratio 3 days after phlebotomy. Iron stores decreased significantly in the liver of phlebotomized mice (Figure 1A). As expected, qRTPCR analysis revealed a $80 \%$ decrease in hepcidin mRNA level in livers of phlebotomized mice (Figure 1B). Accordingly, FPN expression was strongly induced in liver and duodenum whereas we could not detect such induction in spleen extracts. However, the increase in FPN expression was evident in macrophages isolated from the spleen of phlebotomyzed mice (Figure 1C-F). These results were expected as it is well-established that anemia negatively regulates hepcidin, thus increasing the stability of FPN at the cell plasma membrane [6;17].

More interesting were the results obtained from the analysis of FPN mRNA expression following phlebotomy. We found that FPN mRNA level was strongly increased in duodenum and spleen macrophages, whereas its level did not change in the liver and was significantly down-regulated in TER119+-spleen erythroid precursors (Figure 2).

Thus, both changes in mRNA expression and protein stabilization, due to hepcidin downregulation, contibute to regulate FPN expression following phlebotomy. 
Hypoxia regulates FPN transcription in a cell-specific manner

We hypothesized that bleeding-induced hypoxia might be responsible for the tissue-specific regulation of FPN expression. HIF2 $\alpha$ has already been shown to regulate FPN transcription in duodenum [10; 18]. Accordingly, FPN was induced in the intestinal cell line Caco2 following hypoxia (Figure 3A; Figure S1A). Similar results were obtained on Caco2 cells using a known and widely accepted hypoxia-mimicking agent, cobalt chloride (not shown). To assess whether hypoxia was also responsible for FPN up- and down-regulation in macrophages and erythroid progenitors respectively, FPN expression was analyzed in Raw264.7 (macrophage cell line) and K562 (erythroid-like cell line) cells treated for 24 hours with cobalt chloride $\left(\mathrm{CoCl}_{2}\right)$ (Figure S1BC). After $\mathrm{CoCl}_{2}$ incubation, FPN mRNA was up-regulated in Raw264.7 cells and down-regulated in K562 cells (Figure 3B-C). The positive effect on FPN expression was at a transcriptional level, as actynomicin D blocks FPN mRNA induction in Raw264.7 cells in a dose-dependent manner (Figure 3D).

HIF subunits are differentially expressed in cells and tissues

Data reported in the previous paragraph demonstrated that hypoxia may both positively and negatively control FPN transcription. To further investigate this issue we analyzed expression of the different HIF subunits, HIF $1 \alpha, \operatorname{HIF} 2 \alpha$ and $\operatorname{HIF} 3 \alpha$, as it has already been reported that differential expression of these proteins may be responsible for a distinct pattern of cellular expression [19]. The most abundant isoform in Raw264.7 cells was HIF1 $\alpha$ whereas in K562 and Caco2 cells was HIF2 $\alpha$; HIF3 $\alpha$ was expressed at negligible levels in each cell type (Figure 4). The same pattern of HIF subunits expression was also seen in vivo: the most abundant isoform in 
spleen macrophages was HIF1 $\alpha$ whereas in the duodednum and erythroid cells was HIF2 $\alpha$ (not shown).

\section{Discussion}

Here we demonstrated a tissue-specific regulation of FPN mRNA expression following phlebotomy: FPN mRNA increases in tissues that have to supply iron for erythropoiesis and decreases in erythroid progenitors that actively differentiate to recover anemia.

Up-regulation of FPN expression at mRNA level has already been reported in duodenums isolated from mice exposed to hypoxia or fed on iron-deficient diet [3]. Treatment of $\mathrm{CaCo} 2$ cells with iron reduces FPN transcriptional rates while desferrioxamine treatment results in the opposite effect [16]. Moreover, iron loading of human alveolar macrophages [20] and murine J774 macrophages [21] results in increased FPN mRNA. Finally, FPN mRNA levels increase in bone marrow-derived macrophages following erythrophagocytosis and heme treatment, $[11 ; 22 ; 23]$ as well as in Raw264.7 cells after hemoglobin supplementation [13]. Inflammatory stimuli, such as LPS [12], TNF $\alpha$ [24] and turpentine oil [15] can also regulate FPN mRNA levels, both in vivo and in vitro. In addition, it has been reported that high-altitude exposure is associated with an increase in skeletal muscle FPN mRNA levels in humans [14].

Our data indicate that hypoxia consequent to bleeding may be responsible for the tissue-specific regulation of FPN expression as we were able to reproduce in vitro the same pattern of FPN expression observed in vivo by treating Caco2, Raw264.7 and K562 cells with an hypoxic stimulus. However we cannot rule out the possibility that other stimuli induced by bleeding may concur to regulate FPN expression. Among these, erythropoietin (EPO) has been shown to induce 
FPN expression in Caco2 cells [25] and in humans erythropoietin administration affects FPN expression in muscle [26] and in peritoneal exudates macrophages [27]. However, the administration of recombinant human EPO to mice did not affect FPN expression in the duodenum [28]. Whether EPO directly affect FPN promoter has not yet been investigated. Moreover, it has been reported that FPN promoter could be regulated by putative erythroidspecific transcription factors, like GATA and KLF. Accordingly, FPN expression decreased both at the mRNA and protein levels during estradiol-induced erythroid differentiation of G1E-ER4 cells [29]. Our data suggest that HIF may represent an additional transcription factor involved in the regulation of FPN expression at mRNA level in conditions of acute anemia.

We showed that HIF $\alpha$ subunits are differentially expressed in mouse tissues, HIF1 $\alpha$ being mainly expressed in macrophages and HIF $2 \alpha$ in duodenal cells and erythroid progenitors. HIF-1 $\alpha$ and HIF- $2 \alpha$ are characterized by similar structures and both recognize the same DNA sequence. However, differences in their N-terminal activation domain and the requirement of specific transcriptional cofactors confer them specificity in the regulation of gene expression [30]. It has already been demonstrated that HIF1 $\alpha$ and HIF2 $\alpha$ subunits can exhibit opposite roles in the regulation of a single target. As an example, in endothelial cells HIF-1 $\alpha$ diminishes the expression of interleukin-8 (IL-8) by inhibition of the Nrf2 transcription factor, while in the same cells HIF$2 \alpha$ increases the expression of IL- 8 in an Nrf2-independent way. Additionally, HIF-1 decreased, whereas HIF-2 increased, c-Myc expression [30]. Moreover, the complexity of the HIF regulatory system is further increased by the possibility of a single HIF $\alpha$ subunit to induce opposite effects on the same target gene in different cells. Indeed, Fenglan Lou et al. demonstrated that HIF- $2 \alpha$ enhances telomerase reverse transcriptase (hTERT) gene expression in renal cell carcinoma (RCC) cell lines, whereas it represses the hTERT transcription in glioma cells [31]. 
Based on these observations, we speculate that the differential expression of HIF- $1 \alpha$ and HIF- $2 \alpha$, together with tissue-specific co-factors, is responsible for the cell-specific regulation of FPN transcription.

Hypoxia is a main regulator of iron homeostasis as it strongly down-regulates hepcidin [32], likely through a mechanism involving both HIF1 $\alpha$ and HIF2 $\alpha$ [33]. It is intriguing that the same stimulus may both inhibit hepcidin expression and induce its target protein, FPN, in duodenum and macrophages, thus ensuring an adequate iron supply for erythropoiesis. On the other hand, in erythroid precursors hypoxia down-regulates FPN, as shown here, and induces transferrin receptor thus allowing efficient iron utilization [34].

Thus, hypoxia orchestrates a complex regulatory network aimed at ensuring a rapid mobilization of iron from duodenum and macrophages and, on the other hand, at limiting the loss of iron, which is required for hemoglobin synthesis in erythroid precursors (Figure 5).

\section{Acknowledgments}

The authors would like to thank David Haile for the gift of anti-FPN antibody and Radhika Srinivasan for editing of the manuscript.

\section{Authorship}


D.C. performed experiments, analyzed results and wrote the paper; V.F. and S.M. performed some experiments; L.S. supervised experimental work; F.A. designed the research and reviewed the paper; E.T. designed the research, analyzed results, and wrote the paper.

The authors reported no potential conflicts of interest. 


\section{References}

[1] M.W. Hentze, M.U. Muckenthaler, and N.C. Andrews, Balancing acts; molecular control of Mammalian iron metabolism. Cell 117 (2004) 285-97.

[2] S. Abboud, and D.J. Haile, A novel mammalian iron-regulated protein involved in intracellular iron metabolism. J Biol Chem 275 (2000) 19906-12.

[3] A.T. McKie, P. Marciani, A. Rolfs, K. Brennan, K. Wehr, D. Barrow, S. Miret, A. Bomford, T.J. Peters, F. Farzaneh, M.A. Hediger, M.W. Hentze, and R.J. Simpson, A novel duodenal iron-regulated transporter, IREG1, implicated in the basolateral transfer of iron to the circulation. Mol Cell 5 (2000) 299-309.

[4] C. Pigeon, G. Ilyin, B. Courselaud, P. Leroyer, B. Turlin, P. Brissot, and O. Loreal, A new mouse liver-specific gene, encoding a protein homologous to human antimicrobial peptide hepcidin, is overexpressed during iron overload. J Biol Chem 276 (2001) 7811-9.

[5] I. De Domenico, D.M. Ward, C. Langelier, M.B. Vaughn, E. Nemeth, W.I. Sundquist, T. Ganz, G. Musci, and J. Kaplan, The molecular mechanism of hepcidin-mediated ferroportin down-regulation. Mol Biol Cell 18 (2007) 2569-78.

[6] E. Nemeth, M.S. Tuttle, J. Powelson, M.B. Vaughn, A. Donovan, D.M. Ward, T. Ganz, and J. Kaplan, Hepcidin regulates cellular iron efflux by binding to ferroportin and inducing its internalization. Science 306 (2004) 2090-3.

[7] X.B. Liu, P. Hill, and D.J. Haile, Role of the ferroportin iron-responsive element in iron and nitric oxide dependent gene regulation. Blood Cells Mol Dis 29 (2002) 315-26.

[8] A. Lymboussaki, E. Pignatti, G. Montosi, C. Garuti, D.J. Haile, and A. Pietrangelo, The role of the iron responsive element in the control of ferroportin1/IREG1/MTP1 gene expression. J Hepatol 39 (2003) 710-5.

[9] H. Mok, J. Jelinek, S. Pai, B.M. Cattanach, J.T. Prchal, H. Youssoufian, and A. Schumacher, Disruption of ferroportin 1 regulation causes dynamic alterations in iron homeostasis and erythropoiesis in polycythaemia mice. Development 131 (2004) 1859-68.

[10] M. Taylor, A. Qu, E.R. Anderson, T. Matsubara, A. Martin, F.J. Gonzalez, and Y.M. Shah, Hypoxia-inducible factor-2alpha mediates the adaptive increase of intestinal ferroportin during iron deficiency in mice. Gastroenterology 140 (2011) 2044-55.

[11] C. Delaby, N. Pilard, H. Puy, and F. Canonne-Hergaux, Sequential regulation of ferroportin expression after erythrophagocytosis in murine macrophages: early mRNA induction by haem, followed by iron-dependent protein expression. Biochem J 411 (2008) 123-31. 
[12] X.B. Liu, N.B. Nguyen, K.D. Marquess, F. Yang, and D.J. Haile, Regulation of hepcidin and ferroportin expression by lipopolysaccharide in splenic macrophages. Blood Cells Mol Dis 35 (2005) 47-56.

[13] S. Marro, D. Barisani, D. Chiabrando, S. Fagoonee, M.U. Muckenthaler, J. Stolte, R. Meneveri, D. Haile, L. Silengo, F. Altruda, and E. Tolosano, Lack of haptoglobin affects iron transport across duodenum by modulating ferroportin expression. Gastroenterology 133 (2007) 1261-1271.

[14] P. Robach, G. Cairo, C. Gelfi, F. Bernuzzi, H. Pilegaard, A. Vigano, P. Santambrogio, P. Cerretelli, J.A. Calbet, S. Moutereau, and C. Lundby, Strong iron demand during hypoxiainduced erythropoiesis is associated with down-regulation of iron-related proteins and myoglobin in human skeletal muscle. Blood 109 (2007) 4724-31.

[15] N. Sheikh, J. Dudas, and G. Ramadori, Changes of gene expression of iron regulatory proteins during turpentine oil-induced acute-phase response in the rat. Lab Invest 87 (2007) 713-25.

[16] H. Zoller, I. Theurl, R. Koch, A. Kaser, and G. Weiss, Mechanisms of iron mediated regulation of the duodenal iron transporters divalent metal transporter 1 and ferroportin 1. Blood Cells Mol Dis 29 (2002) 488-97.

[17] G. Nicolas, C. Chauvet, L. Viatte, J.L. Danan, X. Bigard, I. Devaux, C. Beaumont, A. Kahn, and $\mathrm{S}$. Vaulont, The gene encoding the iron regulatory peptide hepcidin is regulated by anemia, hypoxia, and inflammation. J Clin Invest 110 (2002) 1037-44.

[18] M. Mastrogiannaki, P. Matak, B. Keith, M.C. Simon, S. Vaulont, and C. Peyssonnaux, HIF2alpha, but not HIF-1alpha, promotes iron absorption in mice. J Clin Invest 119 (2009) 1159-66.

[19] R.H. Wenger, D.P. Stiehl, and G. Camenisch, Integration of oxygen signaling at the consensus HRE. Sci STKE 2005 (2005) re12.

[20] F. Yang, X. Wang, D.J. Haile, C.A. Piantadosi, and A.J. Ghio, Iron increases expression of iron-export protein MTP1 in lung cells. Am J Physiol Lung Cell Mol Physiol 283 (2002) L932-9.

[21] M.D. Knutson, M.R. Vafa, D.J. Haile, and M. Wessling-Resnick, Iron loading and erythrophagocytosis increase ferroportin 1 (FPN1) expression in J774 macrophages. Blood 102 (2003) 4191-7.

[22] C. Delaby, N. Pilard, G. Hetet, F. Driss, B. Grandchamp, C. Beaumont, and F. CanonneHergaux, A physiological model to study iron recycling in macrophages. Exp Cell Res 310 (2005) 43-53. 
[23] S. Marro, D. Chiabrando, E. Messana, J. Stolte, E. Turco, E. Tolosano, and M.U. Muckenthaler, Heme controls ferroportin1 (FPN1) transcription involving Bach1, Nrf2 and a MARE/ARE sequence motif at position -7007 of the FPN1 promoter. Haematologica 95 (2010) 1261-8.

[24] A.H. Laftah, N. Sharma, M.J. Brookes, A.T. McKie, R.J. Simpson, T.H. Iqbal, and C. Tselepis, Tumour necrosis factor alpha causes hypoferraemia and reduced intestinal iron absorption in mice. Biochem J 397 (2006) 61-7.

[25] S.K. Srai, B. Chung, J. Marks, K. Pourvali, N. Solanky, C. Rapisarda, T.B. Chaston, R. Hanif, R.J. Unwin, E.S. Debnam, and P.A. Sharp, Erythropoietin regulates intestinal iron absorption in a rat model of chronic renal failure. Kidney Int 78 (2010) 660-7.

[26] P. Robach, S. Recalcati, D. Girelli, C. Gelfi, N.J. Aachmann-Andersen, J.J. Thomsen, A.M. Norgaard, A. Alberghini, N. Campostrini, A. Castagna, A. Vigano, P. Santambrogio, T. Kempf, K.C. Wollert, S. Moutereau, C. Lundby, and G. Cairo, Alterations of systemic and muscle iron metabolism in human subjects treated with low-dose recombinant erythropoietin. Blood 113 (2009) 6707-15.

[27] W.N. Kong, S.E. Zhao, X.L. Duan, Z. Yang, Z.M. Qian, and Y.Z. Chang, Decreased DMT1 and increased ferroportin 1 expression is the mechanisms of reduced iron retention in macrophages by erythropoietin in rats. J Cell Biochem 104 (2008) 629-41.

[28] W.N. Kong, Y.Z. Chang, S.M. Wang, X.L. Zhai, J.X. Shang, L.X. Li, and X.L. Duan, Effect of erythropoietin on hepcidin, DMT1 with IRE, and hephaestin gene expression in duodenum of rats. J Gastroenterol 43 (2008) 136-43.

[29] D.L. Zhang, R.M. Hughes, H. Ollivierre-Wilson, M.C. Ghosh, and T.A. Rouault, A ferroportin transcript that lacks an iron-responsive element enables duodenal and erythroid precursor cells to evade translational repression. Cell Metab 9 (2009) 461-73.

[30] U. Florczyk, S. Czauderna, A. Stachurska, M. Tertil, W. Nowak, M. Kozakowska, L. Poellinger, A. Jozkowicz, A. Loboda, and J. Dulak, Opposite effects of HIF-1alpha and HIF-2alpha on the regulation of IL-8 expression in endothelial cells. Free Radic Biol Med 51 (2011) 1882-92.

[31] F. Lou, X. Chen, M. Jalink, Q. Zhu, N. Ge, S. Zhao, X. Fang, Y. Fan, M. Bjorkholm, Z. Liu, and $\mathrm{D}$. $\mathrm{Xu}$, The opposing effect of hypoxia-inducible factor-2alpha on expression of telomerase reverse transcriptase. Mol Cancer Res 5 (2007) 793-800.

[32] T. Ganz, and E. Nemeth, Iron imports. IV. Hepcidin and regulation of body iron metabolism. Am J Physiol Gastrointest Liver Physiol 290 (2006) G199-203. 
[33] C. Peyssonnaux, A.S. Zinkernagel, R.A. Schuepbach, E. Rankin, S. Vaulont, V.H. Haase, V. Nizet, and R.S. Johnson, Regulation of iron homeostasis by the hypoxia-inducible transcription factors (HIFs). J Clin Invest 117 (2007) 1926-32.

[34] C.N. Lok, and P. Ponka, Identification of a hypoxia response element in the transferrin receptor gene. J Biol Chem 274 (1999) 24147-52. 


\section{Legends for Figures}

\section{Figure 1. Regulation of FPN expression following phlemotomy.}

(A) Phlemotomy model. Hematological parameters, liver iron and spleen/body weight ratio in untreated and phlebotomized mice 1, 3 and 7 days after the first bleeding. Data represent mean \pm SEM; $\mathrm{n}=10$ for each experimental point. * $=\mathrm{P}<0.05$; ** $=\mathrm{P}<0.01$; *** $=\mathrm{P}<0.001$. (B) qRT-PCR analysis of hepcidin expression in the liver of untreated and phlebotomized mice, 3 days after the first bleeding. Transcript abundance, normalized to 18S RNA expression, is expressed as a fold increase over a calibrator sample. Data represent mean $\pm \mathrm{SEM} ; \mathrm{n}=5 ; * * *=\mathrm{P}<0.001$. Results shown are representative of 3 independent experiments. (C-F) Western blots of FPN expression in liver, duodenum, spleen and $\mathrm{CD} 11 \mathrm{~b}+$ cells isolated from the spleen of untreated and phlebotomized mice, 3 days after the first bleeding. A representative experiment for each tissue is shown. Band intensities were measured by densitometry and normalyzed to actin expression. Data represent mean $\pm \mathrm{SEM} ; \mathrm{n}=3$ for each experimental point. $* *=\mathrm{P}<0.01$; $* * *=\mathrm{P}<0.001$.

Figure 2. Cell-specific transcriptional regulation of FPN after phlebotomy. qRT-PCR analysis of FPN expression in liver (A) duodenum (B) spleen CD11b+ cells $(\mathbf{C})$ and spleen TER119+ cells (D) of untreated and phlebotomized mice, 3 days after the first bleeding. Transcript abundance, normalized to 18S RNA expression, is expressed as a fold increase over a calibrator sample. Data represent mean $\pm \mathrm{SEM} ; \mathrm{n}=3 ; *=\mathrm{P}<0.05$. Results shown are representative of 3 independent experiments. 
Figure 3. Hypoxia controls FPN transcription. (A) qRT-PCR analysis of FPN mRNA levels in Caco-2 cells following 6, 24 and 48 hours of hypoxia (1\% oxygen). (B) qRT-PCR analysis of FPN mRNA levels in RAW 264.7 and K562 cells treated for 8, 12, 18 or 24 hours with $100 \mu \mathrm{M}$ $\mathrm{CoCl}_{2}$. (D) qRT-PCR analysis of FPN expression in RAW264.7 treated for 24 hours with $100 \mu \mathrm{M}$ $\mathrm{CoCl}_{2}$ and increasing amounts of actinomycin D. Transcript abundance, normalized to $18 \mathrm{~S}$ RNA expression, is expressed as a fold increase over a calibrator sample. Data represent mean $\pm \mathrm{SEM}$; $\mathrm{n}=3 ; *=\mathrm{P}<0.05 ; * * *=\mathrm{P}<0.001$. Results shown are representative of 3 independent experiments.

Figure 4. Differential expression of HIF $\alpha$ subunits. qRT-PCR analysis of HIF1 $\alpha$, HIF2 $\alpha$ and HIF3 $\alpha$ expression in RAW264.7 (A), K562 (B) and Caco-2 (C) cells. Transcript abundance, normalized to 18S RNA expression, is expressed as a fold increase over a calibrator sample. Data represent mean $\pm \mathrm{SEM} ; \mathrm{n}=3$ for each experimental point; $* *=\mathrm{P}<0.01 ; * * *=\mathrm{P}<0.001$. Results shown are representative of 3 independent experiments.

Figure 5. Cell-specific transcriptional regulation of FPN is mediated by different HIF subunits. We hypothesized that hypoxia may stabilize different HIF $\alpha$ subunits in different cell types. Stabilization of HIF1 $\alpha$ in macrophages, in association with the constitutive HIF1 $\beta$ isoform, activates the transcription of FPN mRNA. HIF2 $\alpha$ plays a role in the transcriptional activation of FPN mRNA in the duodenum [10]. In this manner hypoxia contributes at the transcriptional level to increase FPN expression in duodenum and macrophages, thus allowing increased iron absorption and mobilization to support erythropoiesis. 
Data reported here suggested that HIF2 $\alpha$ could inhibit FPN transcription in erythroid progenitors. The down-regulation of FPN protein may be important to increase iron availability for heme synthesis in erythroid progenitors.

We hypothesized that the association of HIF2 $\alpha$ with cell-specific transcriptional activators or repressors could account for the differential role of HIF $2 \alpha$ in modulating the transcription of FPN in duodenum and erythroid precursors. 
A

\begin{tabular}{|c|c|c|c|c|}
\hline & 0 days & 1 days & 3 days & 7 days \\
\hline HCT (\%) & $4: 3,51 \pm 0,59(n=12)$ & $33,95 \pm 1,09 * \star *(n=11)$ & $27,39 \pm 1,60 * * *(n=8)$ & $39,0 \pm 0,60 * *(n=8)$ \\
\hline $\operatorname{RBC}\left(10^{\wedge} 12 / L\right)$ & $\mathrm{c}, 14 \pm 0,15(\mathrm{n}=12)$ & $7,03 \pm 0,25 * \star * *(n=11)$ & $5,03 \pm 0,33^{* \star *}(n=8)$ & $7,15 \pm 0,28 * * *(n=8)$ \\
\hline HGB (g/dL) & $1: 3,58 \pm 0,20(n=12)$ & 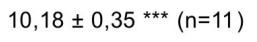 & $7,64 \pm 0,48{ }^{* \star *}(n=8)$ & $11,37 \pm 0,13^{* \star *}(n=8)$ \\
\hline RET (\%) & $3,45 \pm 0,48(n=12)$ & $4,51 \pm 0,44(n=11)$ & $7,44 \pm 0,61^{* * *}(n=8)$ & $8,35 \pm 1,06^{* * *}(n=8)$ \\
\hline $\operatorname{MCV}(\mathrm{fL})$ & $47,48 \pm 0,23(n=12)$ & $48,28 \pm 0,40(n=11)$ & $54,79 \pm 0,78^{* \star \star}(\mathrm{n}=8)$ & $54,45 \pm 0,97^{* * *}(n=8)$ \\
\hline Liver Iron $(\mu \mathrm{g} / \mathrm{g})$ & $292.8 \pm 19.90(n=8)$ & 1 & $236.9 \pm 13.12 *(n=8)$ & $189.0 \pm 27.42^{* *}(\mathrm{n}=5)$ \\
\hline Splenic weight ratio & $5.65 \pm 0.43(n=6)$ & 1 & $11.56 \pm 0.70 * * *(n=3)$ & \\
\hline
\end{tabular}

B Hepc mRNA

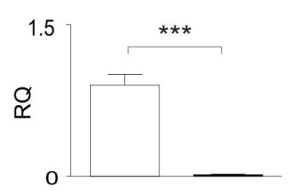

E Spleen

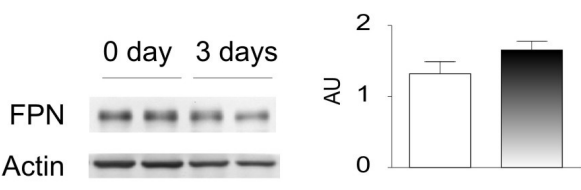

\section{Duodenum}

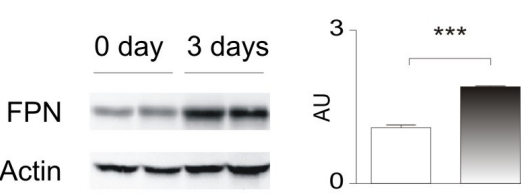

0 day 3 days

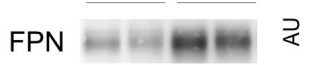

Actin

F Spleen macrophages

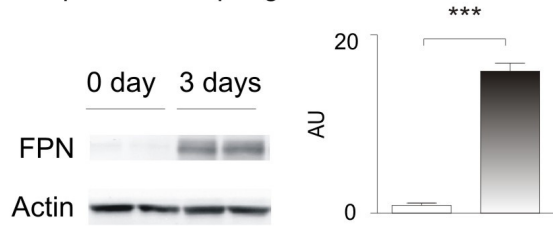

$\square$ Untreated mice $\square$ Phlebotomized mice

Figure 1 
A Liver

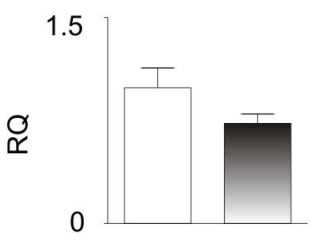

C CD11b+cells

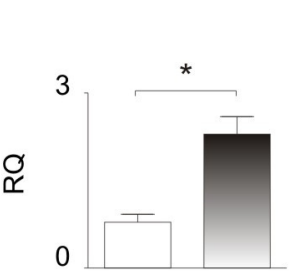

$\square$ Untreated mice
B Duodenum

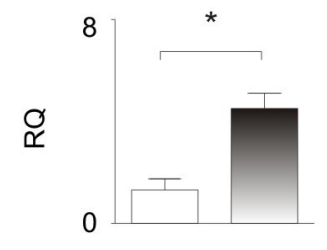

D TER119+ cells

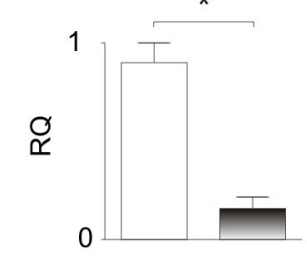

Phlebotomized mice

Figure 2 


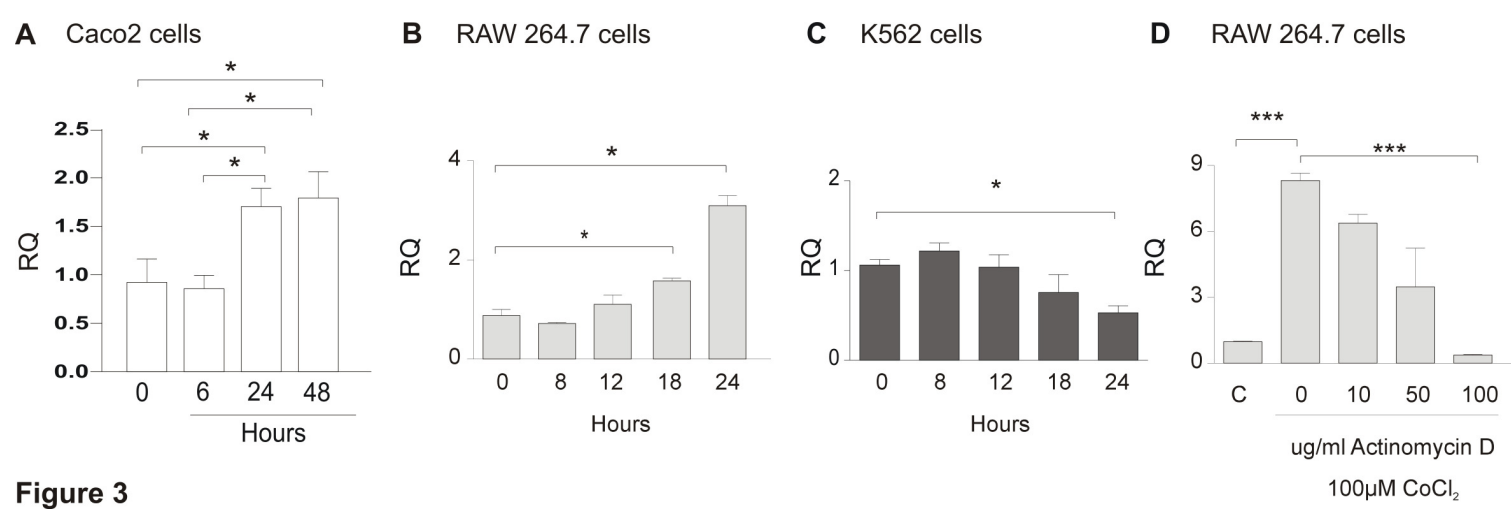



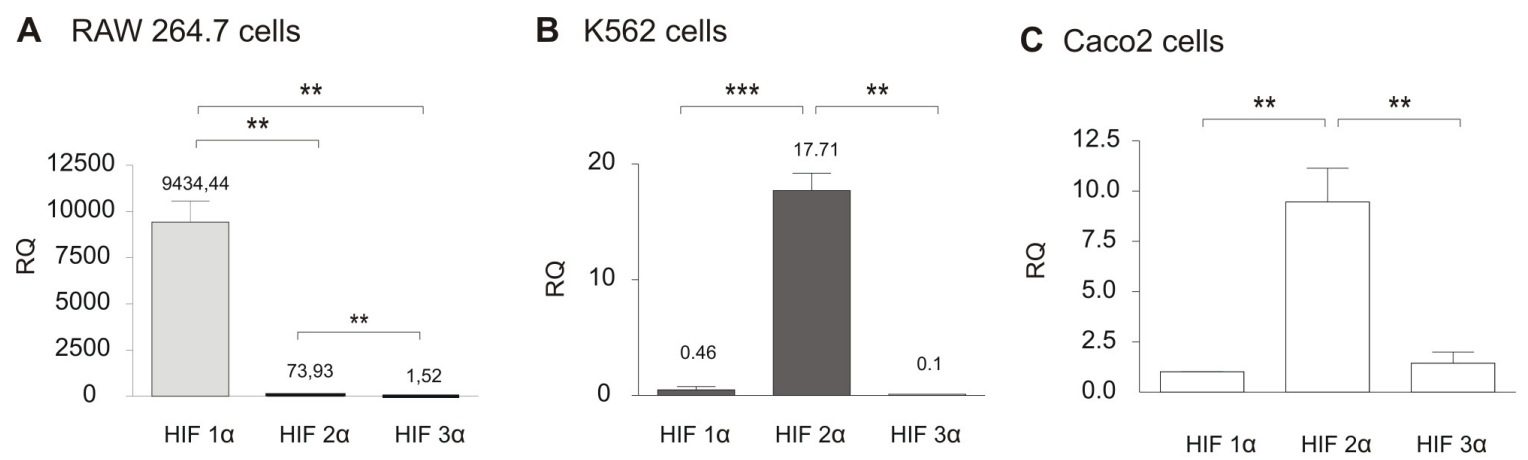

Figure 4 


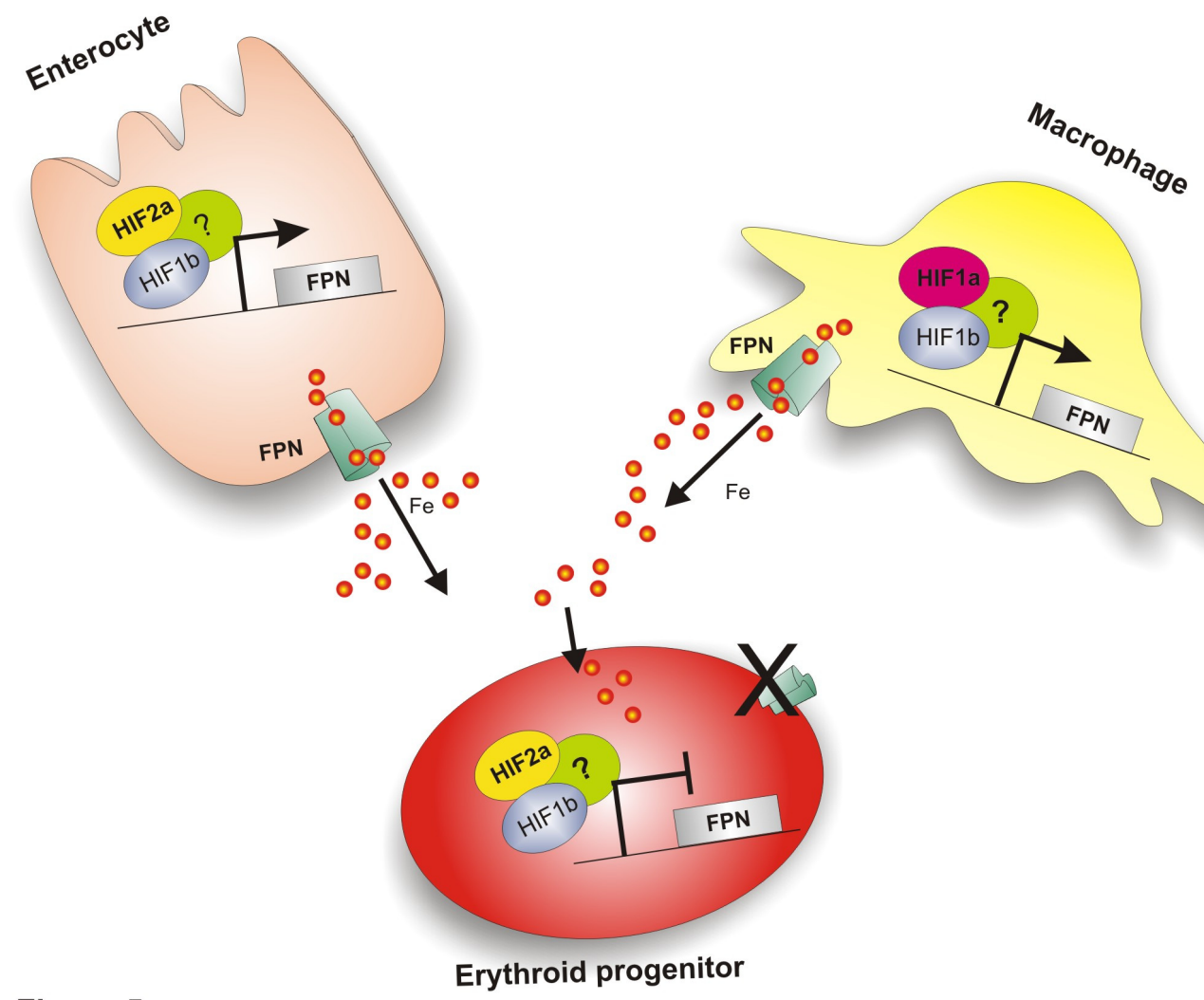

Figure 5 